\title{
JULGAMENTO DA TERRA INDÍGENA RAPOSA SERRA DO SOL:TODO DIA ERA DIA DE ÍNDIO
}

\author{
Erica Magami Yamada e Luiz Fernando Villares
}

RAPOSA SERRA DO SOL INDIGENOUS LAND TRIAL

\section{RESUMO}

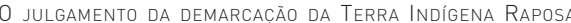
SERRA do SOL EXPÔS O PAPEL dO STF COMO LEgISLADOR POSITIVO. O RECÉM-PUBLICADO ACÓRDÃO DO STF SOBRE O CASO AGREGA AS CHAMADAS SALVAGUARDAS INSTITUCIONAIS FORMULADAS NAS 19 RESSALVAS À ACÃO DO PODER EXECUTIVO E AOS DIREITOS DOS POVOS INDÍGENAS APRESENTADAS EM PLENÁRIA. ALGUMAS DESSAS RESSALVAS, VERDADEIROS ENUNCIADOS NORMATIVOS, AMEAÇAM RETROCEDER O RECONHECIMENTO DE DIREITOS DE MINORIAS ÉTNICAS NO PAÍS, NA CONTRAMÃO DE COMPROMISSOS INTERNACIONAIS DE DIREITOS HUMANOS ASSUMIDOS, ESPECIALMENTE QUANTO À INTERPRETACCÃO DO DIREITO ORIGINÁRIO DOS ÍNDIOS SOBRE SUAS TERRAS TRADICIONAIS E QUANTO AO NÃO RECONHECIMENTO DA ORGANIZAC̣ÃO POLITICA INDÍGENA COM O CONTROLE SOBRE SUAS TERRAS.

\section{PALAVRAS-CHAVE}

Supremo Tribunal Federal; Terra indígena Raposa SERRA DO SOL; POVOS INDÍGENAS; DIREITOS TERRITORIAIS; ENUNCIADOS NORMATIVOS.

\section{ABSTRACT}

THE TRIAL TO DEMARCATE THE INDIGENOUS LAND RAPOSA SERRA DO SOL REVEALED THE ROLE OF THE STF AS A POSITIVE LEGISLATOR. THE RECENTLY PUBLISHED DECISION ON THE CASE INCORPORATED THE SO CALLED INSTITUTIONAL SAFEGUARDS INTRODUCED BY THE 19 CONDITIONS TO THE EXECUTIVE ACTION AND TO INDIGENOUS PEOPLES RIGHTS AS PRESENTED DURING THE HEARINGS.

SOME OF THESE SAFEGUARDS, ACTUAL NORMATIVE STATEMENTS, THREATEN TO MOVE BACKWARDS THE RECOGNITION OF MINORITY ETHNIC GROUPS IN BRAZIL. THEY GO AGAINST THE INTERNATIONAL COMMITMENTS OF THE STATE TOWARDS HUMAN RIGHTS, PARTICULARLY REGARDING THE INTERPRETATION OF INDIGENOUS PEOPELS ORIGINAL RIGHT TO LANDS AND THE NON-RECOGNITION OF THE INDIGENOUS POLITICAL ORGANIZATION A CAPACITY TO CONTROL THEIR OWN LANDS.

\section{KEYWORDS}

BRAZILIAN SUPREME COURT; INDIGENOUS LAND RAPOSA SERRA DO SOL; INDIGENOUS PEOPLES; TERRITORIAL RIGHTS; NORMATIVE STATEMENTS.

$\mathrm{S}$ entada, uma mulher de túnica branca e venda nos olhos, repousa em suas pernas uma leve espada. Ela está à frente do prédio do Supremo Tribunal Federal, na Praça dos Três Poderes, em Brasília, capital do Brasil. A representação modernista de Alfredo Ceschiatti ${ }^{1}$ para “justiça” é alta, magra, calma e elegante.

Dentro do prédio de proporções relativamente reduzidas, parecendo flutuar na nobreza e dignidade de suas galerias externas, revestidas do mais branco dos mármores, 
se ouve uma campainha estridente que anuncia o início da seção e a entrada dos onze ministros no plenário. Todos os presentes se levantam, para reverenciar os onze ministros e o Procurador-Geral da República. Por cima do terno, eles vestem uma toga preta e comprida, que contrasta com o tom dourado do carpete, o bege da parede de mármore e o marrom-claro da madeira das bancadas do plenário do STF.

A toga comprida, tradição de nosso Poder Judiciário, diferencia os ministros dos demais. Ainda que você participe do julgamento como advogado ou membro do Ministério Público terá que usar uma toga mais curta. Contraditoriamente, o edifício de Oscar Niemeyer envolve, aproxima e coloca quase na mesma altura os juízes e a plateia dos cidadãos. Eles se sentam no balcão em forma de "U", auxiliados pelos seus meirinhos.

Existe uma norma rígida que define o assento no plenário do STF. O presidente se senta na ponta central do balcão. Ao seu lado direito tem assento o procuradorgeral da República e do lado esquerdo o secretário da seção. O último ministro nomeado senta-se na cadeira mais distante, à esquerda do presidente. O penúltimo, na cadeira mais distante, à direita. Alternam-se os demais até a cadeira mais próxima, à direita do presidente, onde fica sentado o decano.

No painel de mármore bege de Athos Bulcão, em cima da cadeira do presidente, um brasão de bronze da República do Brasil. Mais vistoso é o Jesus crucificado acima e à esquerda. A bandeira do Brasil, verde, amarela e azul quebra a monocromia desse altar.

Em um dia normal a plateia não tem mais do que cinquenta pessoas para uma lotação máxima de 376 pessoas. Mas esse é um grande dia, em que será julgado o caso que envolve a demarcação da Terra Indígena Raposa Serra do Sol, em Roraima. A plateia aguardava ansiosa o início do julgamento. A primeira fileira sempre reserva seus lugares para o Advogado-Geral da União e os advogados das partes dos processos a serem julgados. O procurador-geral do Estado de Rondônia, o senador Mozarildo Cavalcanti, o ex-ministro do STF, Francisco Rezek, e outros advogados eram os representantes do Estado de Roraima e dos fazendeiros contrários à demarcação. A favor da demarcação, a advogada indígena Joênia Wapixana, representante dos povos indígenas da Raposa Serra do Sol, advogados do Conselho Indigenista Missionário, procuradores da República do Ministério Público Federal, procuradores da Funai, representantes da Advocacia-Geral da União. Ministros, senadores, deputados, prefeitos, funcionários públicos, integrantes das forças armadas, ONGs, todos queriam acompanhar de perto a sessão. O caso, com repercussão nacional, atraiu uma grande quantidade de ilustres convidados. A figura mais festejada era a senadora Marina Silva, ex-ministra do meio ambiente e figura máxima da luta pela Amazônia. Mas quem dava colorido especial ao julgamento eram as diversas lideranças indígenas do Brasil, com toda pompa de seus trajes de gala. Suas penas e tintas contrastavam com a sobriedade reinante dos brancos em longos trajes negros. 
Lotação esgotada, a fila antes da sessão começara a se formar de madrugada. Na sala ao lado, fora necessário instalar um telão para aqueles que não tinham seus lugares reservados no plenário para acompanhar o julgamento. Quase uma centena de jornalistas. Com direito ao lugar mais elevado da plateia frontal estavam cinegrafistas e fotógrafos que tudo observavam. Diversos canais de televisão, emissoras de rádio e jornais relatavam o caso em informes a cada minuto, acrescentados de relatos, expectativas, opiniões, análises e prognósticos. A TV Justiça e a Rádio Justiça, órgãos de comunicação vinculados diretamente ao STF, transmitiam ao vivo o julgamento.

Essas e outras razões tiram o STF de sua rotina, fazendo-o acordar mais cedo e dormir mais tarde. As sessões plenárias do STF são realizadas geralmente às quartas e quintas-feiras, na parte da tarde, entre as 14 e 18 horas. Porém, a complexidade do caso e sua visibilidade supõem um julgamento longo. O presidente tem a atribuição de estabelecer os dias e horários dos julgamentos, escolhendo para esse caso a primeira hora da manhã de uma quarta-feira, prevendo a duração da sessão até o dia seguinte.

Ainda que acostumados a julgamentos polêmicos e ruidosos, índios de diversas etnias e de todos os lugares do país, que prestam solidariedade aos povos da Raposa Serra do Sol, causam um estranho nervosismo ao STF, como se um enfrentamento real pudesse emergir de uma palavra mau posta. O índio ainda representa o estranho, o selvagem nu (ou de calção e havaianas), com pintura cerimonial colorida, ruidoso, com linguagem direta e aparente falta de hierarquia. Tudo a contrastar e enfrentar a sobriedade e o requinte da Corte, expondo que esses dois mundos dificilmente se conciliam, ao contrário se repelem em uma inquietante discriminação.

Mas chega a hora de exercer o poder. Todos sentados, o silêncio se impõe. O presidente lê e propõe a aprovação da ata da reunião anterior. Após a cotidiana formalidade, é iniciada a sessão ordinária, com a leitura da ordem do dia, que traz a relação dos processos a serem julgados. Passa-se, então, a palavra ao ministro relator do processo.

O ministro Carlos Ayres Britto começa a ler o relatório preparado anteriormente e distribuído aos demais ministros através da rede de comunicação interna do STF, visível nos computadores portáteis de cada ministro. O relatório traz informações do processo, como as partes envolvidas, a descrição do tipo de ação ou recurso que foi ajuizado perante o tribunal, as alegações do autor e do réu, os pedidos formulados, a posição do Ministério Público, as decisões já tomadas, etc. Tendo em vista a dificuldade do caso, ${ }^{2}$ a leitura do relatório do caso da Raposa Serra do Sol se prolongou mais do que o costume.

Formalidade indispensável, a leitura do relatório é monótona para os ministros, ainda que acompanhada por todo o público com atenção. Antes do julgamento um sem número de audiências foi realizada com todas as partes e diversos memoriais, ${ }^{3}$ 
foram apresentados, assim como manifestações de vários órgãos da sociedade se posicionando sobre a ação. Para se ter uma ideia da visibilidade do caso narrado neste artigo, em 2008, três ministros do STF - o presidente Gilmar Mendes, o relator do processo, Carlos Britto, e a ministra Carmen Lúcia - sobrevoaram o local da controvérsia e aterrissaram na aldeia Serra do Sol, no norte do Estado de Roraima, numa espécie de diligência judicial, para conhecer de perto a região e fazer um juízo mais apurado da questão.

Lido o relatório, uma questão de ordem ${ }^{4}$ foi colocada à resolução dos ministros antes de o relator iniciar seu voto. Decidiu-se que as entidades e pessoas que peticionaram para ingressar na ação seriam admitidas como assistentes das partes. Com isso, essas entidades conseguiram autorização para fazer sustentação oral no plenário, apresentar memoriais, mas não poderiam intervir no processo e juntar provas, evitando, assim, um desnecessário alongamento da causa, que já estava apta a ser resolvida.

Superada essa fase, foram convidados os advogados dos autores, seguidos dos advogados dos réus, para sua sustentação oral. Pela primeira vez, um indígena pôde falar do alto do púlpito com os ministros. Nascida numa aldeia do interior de Roraima a advogada Joênia Wapixana representou o seu povo e fez uma emocionada defesa no Supremo Tribunal Federal. ${ }^{5}$ Vestia a indefectível toga preta, para ser admitida como oradora, mas seu rosto estava pintado, para lembrar a todos que sua identidade se sobrepunha ao formalismo.

Terminadas as manifestações orais das partes e do Ministério Público Federal, o ministro relator do caso profere seu voto. A leitura do voto, já redigido, pelo relator durou não menos que três horas. Conhecido pela sua proximidade às questões sociais, o ministro Carlos Britto foi absolutamente favorável à demarcação, afastando cada um dos argumentos contrários, tanto de fundo jurídico como político.

O segundo a votar, depois do relator, é o último ministro nomeado, Carlos Alberto Menezes Direito. De forma esperada ${ }^{6}$ esse ministro pediu vista do processo, interrompendo seu julgamento. O pedido de vista é uma faculdade do ministro para analisar melhor a ação. Na prática, é utilizado para diversos fins, entre eles: o oferecimento de voto divergente ao relator na retomada do julgamento; retirar o processo do foco de atenção da sociedade ainda que de forma momentânea; falta de clareza sobre algum ponto a ser julgado; possibilidade de convencimento dos demais ministros a ser feita nos bastidores.

Pelos debates e decisões de julgamentos anteriores ${ }^{7}$ ou pelos posicionamentos políticos ao longo das carreiras, em tese, em uma ponta estariam o ministro Joaquim Barbosa e Ricardo Lewandowski, como defensores dos direitos dos povos indígenas; de outro lado, em uma posição de restrição de direitos indígenas, os ministros César Peluso e Gilmar Mendes, e, como absolutamente contrário aos direitos indígenas, o ministro Marco Aurélio. Esperava-se dos outros ministros (Celso de Mello, Ellen Gracie, Eros Grau e Carmen Lúcia) uma posição favorável à demarcação. 
O julgamento, iniciado em 27.08.2008, foi retomado em dezembro do mesmo ano, com o oferecimento do voto parcialmente divergente do ministro Menezes Direito. Ciente de que um voto contrário à demarcação contínua da Terra Indígena não seria bem recebido pela maioria do plenário, o que o colocaria numa posição desconfortável, esse ministro estabeleceu 19 condicionantes ${ }^{8}$ - ou ressalvas - às demarcações de terras indígenas realizadas pelo Poder Executivo no cumprimento do art. 231 da Constituição.

As 19 ressalvas pretensamente procuravam conciliar os interesses indígenas, a defesa nacional e a preservação do meio ambiente. Algumas são interpretações ou repetições do texto constitucional e legal (as de número 1, 2, 3, 4, 14, 15, 16, 18), outras, comandos contrários aos já estabelecidos na Convenção 169 da Organização Internacional do Trabalho (OIT) $(5,6,7)$, e em regulamentação infralegal $(8,9$ e 10). Ainda, a criação de enunciados normativos pelas ressalvas 11, 12, 13, 17 e 19 . Este artigo concentrará sua análise nas condicionantes que inovam o ordenamento.

Após o voto de Menezes Direito, o ministro Marco Aurélio Melo adiantou seu pedido de vista do processo e solicitou a interrupção do julgamento. No entanto, esse pedido antecipado representaria uma quebra na ordem do julgamento, pois outros ministros deveriam votar antes de Marco Aurélio Melo. Depois de acalorado debate sobre o prosseguimento ou não do julgamento, o presidente do SFT, ministro Gilmar Mendes, decidiu não acatar o pedido de vista imediatamente. Passaram a votar favoravelmente pela demarcação da Terra Indígena, nesta ordem, os ministros Carmen Lúcia, Ricardo Lewandowski, Eros Grau, Joaquim Barbosa, Cezar Pelluso, atingindo o pedido de vista do ministro Marco Aurélio Mello. O julgamento foi então interrompido novamente, com previsão de se ser concluído apenas em 2009.

No terceiro dia de julgamento, 18.04.2009, o ministro Marco Aurélio Mello lê seu voto de seis horas contrário à demarcação. Como sói acontecer, Marco Aurélio tem posição radicalmente divergente dos demais. Celso de Mello, o ministro mais antigo em atividade, vota a favor da demarcação. A sessão é interrompida, o julgamento promete ser encerrado no dia seguinte.

Ao ser retomado o julgamento, Gilmar Mendes proferiu seu voto a favor da demarcação e das ressalvas. Diga-se que o único veementemente contrário às ressalvas foi o ministro Joaquim Barbosa, votando pela total improcedência da ação. Tal posicionamento coaduna-se com sua formação de membro do Ministério Público Federal, instituição aguerrida na defesa dos direitos dos povos indígenas e tradicionais. Os outros seguiram os votos do ministro Carlos Britto, "complementado" pelas condicionantes trazidas pelo ministro Menezes Direito.

Por fim, os ministros discutiram em que prazo deveria ser aplicada sua decisão, confiando ao relator a definição posterior ao julgamento e ao presidente do Tribunal Federal Regional da $1^{\text {a }}$ Região o acompanhamento e supervisão de sua execução. 


\section{i Análise do julgamento do caso Raposa Serra do Sol}

A longa descrição do julgamento da Petição n. 3.388 em Ação Popular mostra que ao STF foi submetida mais que uma questão jurídica. A disputa pelo território entre índios e não índios foi resolvida por diversas formas ao longo da história de nosso País, inclusive com reconhecimento de direitos dos indígenas desde a chegada dos primeiros colonizadores europeus. A ideia de reconhecer formalmente direitos indígenas - ainda que por vezes com fundamento humanista -, na maior parte das vezes, teve como intuito facilitar a apropriação de terras e recursos daqueles, e ainda influencia a relação do Estado com os povos indígenas9 (YAMADA, 2009, p.14). No mais das vezes, o estabelecimento de normas, e suas interpretações, que dizem respeito a povos indígenas se dá pela necessidade de remediar situações de conflito entre índios e não índios, e não como forma de reconhecer direitos de maneira equitativa ou prevenir a violação de direitos indígenas.

A atuação do Estado brasileiro como mediador desse conflito é marco da nossa República, iniciada em decorrência da missão de um homem, o então coronel Cândido Rondon, quando do avanço das linhas telegráficas pelo interior norte do país (GOMES, 2009), e que prosseguiu com a institucionalização de uma política indigenista com a criação do Serviço de Proteção aos Índios (SPI) em 1910.

Caráter importante do relacionamento do Brasil com os povos indígenas foi a demarcação e garantia de seus territórios, ainda que de forma vacilante, pelo Poder Executivo ao longo do século 20. Para isso, sempre foi necessária uma definição legislativa, ainda que incompleta, dos direitos territoriais e sociais dos povos indígenas. A Constituição de 1988 veio para ampliar e tornar indiscutível a proteção aos povos indígenas, em linha com o que internacionalmente se estabeleceu como direito fundamental para eles no século 21.

O julgamento pelo STF da demarcação da Terra Indígena Raposa Serra do Sol pelo STF é o mais recente marco de reavaliação e mudança na política indigenista brasileira. É cedo para se perguntar quais as suas implicações, o que mudou. Este artigo será o primeiro trabalho acadêmico a enfrentar a questão tão recente.

O primeiro grande resultado, sem dúvida, foi garantir aos povos indígenas Ingaricó, Macuxi, Patamona, Taurepangue, e Uapixana o reconhecimento de suas terras, base material da sua vida, local de morada onde são desenvolvidas suas relações familiares e econômicas, e do qual retiram seu alimento e propagam sua religiosidade e cultura. Respeitou-se a tradição jurídica do reconhecimento dos territórios indígenas e da não aceitação do esbulho como forma de aquisição de propriedade.

Ainda que mantida a política do reconhecimento de um território contínuo para cinco povos indígenas, o caso Raposa Serra do Sol ganhou repercussão nacional e internacional por mostrar a dificuldade de se construir uma sociedade verdadeiramente diversa e democrática a partir do respeito e da proteção dos direitos humanos dos povos indígenas, tal como reconhecidos na Constituição brasileira. Revelou também 
que os governos locais veem e promovem os indígenas como estrangeiros em seus próprios territórios, ignorando suas importantes contribuições nas relações sociais e econômicas dos estados e municípios.

Até agora nenhuma grande novidade, tendo em vista que a promulgação de uma nova Constituição não tem o condão de alterar a história de forma imediata, mas proporcionar uma ação da sociedade e do Estado para perseguir o idealizado.

A demarcação da Raposa Serra do Sol foi elevada pelo Supremo Tribunal Federal a caso paradigmático porque se fez crer que, pela primeira vez, o STF analisaria a fundo o mérito da questão de terras indígenas no país. O STF, no entanto, reafirmou de forma vacilante a aplicação da Constituição de 1988. Como em tantos outros casos pendentes ${ }^{10}$ a indefinição do Poder Judiciário em relação à Raposa Serra do Sol revelou que a falta de segurança jurídica de direitos administrativamente reconhecidos contribui para o agravamento da situação de conflito entre povos indígenas e ocupantes não índios. Infelizmente, o caso concreto - que pedia uma solução rápida -, importou menos que a vontade de legislar, transformando o julgamento em espetáculo, o que tem marcado as últimas decisões do Supremo.

Em cena, o STF reconheceu a legalidade do processo administrativo da demarcação da Terra Indígena Raposa Serra do Sol. Mais que isso, não encontrou ofensa à soberania nacional ou segurança territorial na demarcação de terras indígenas em área contígua e faixa de fronteira; rechaçou a possibilidade de a demarcação de terras indígenas ameaçar o princípio federativo e o desenvolvimento da nação; e reconheceu a proteção dos povos e culturas distintas que compõem a nação brasileira.

No entanto, o STF impôs condicionantes que podem alcançar todos os povos indígenas do Brasil, com contradições que ainda revelam o espírito discriminatório que se sobrepõe ao ideal constitucional do pluralismo democrático. $\mathrm{O}$ voto vencedor trouxe 19 condicionantes que, em tese, poderão balizar qualquer reconhecimento de terras indígenas em nosso País. Algumas extrapolaram o papel designado ao STF pela Constituição, como se o ator pudesse inventar falas de seu personagem, modificando o roteiro constitucional.

O Poder Judiciário sempre é festejado quando rompe a clássica doutrina da separação de poderes e toma a iniciativa ao implementar direitos sociais, mediante provimentos jurisdicionais que acabam por inovar a legislação existente, complementando direitos geralmente expressos em textos de grande abertura (PINHEIRO, 2009, p. 20). ${ }^{11}$ A questão chega ao Supremo quando do anúncio e realização de audiências públicas cujos assuntos passam pela interrupção da gravidez de feto anencéfalo; reiteradas decisões judiciais para garantir os mais diferentes medicamentos, insumos, tratamentos e produtos de saúde; cotas raciais e reserva de vagas nas universidades públicas entre outras decisões.

Mas será também festejado quando limitar esses mesmos direitos sociais, impondo restrições não previstas constitucionalmente? 
Este artigo concentrará sua reflexão nas ressalvas trazidas pelo julgamento do caso Raposa Serra do Sol que inovaram o ordenamento jurídico brasileiro, deixando de lado aquelas que são interpretações ou repetições do texto constitucional e legal. O sentimento geral é que a decisão, aparentemente benéfica aos povos indígenas, embutiu no reconhecimento territorial um grande retrocesso em relação aos seus direitos, como veremos a seguir.

A maior e mais impactante das definições não está presente na enumeração das condicionantes às demarcações de terras indígenas. O reconhecimento das terras ocupadas pelos povos indígenas no dia 05.10.1988, quando da promulgação da Constituição, está no corpo da decisão. O Exmo. Ministro Ricardo Lewandowski disse que essa data representaria uma espécie de "fotografia" do momento. O próprio relator, ministro Ayres Britto, chamou-a de "chapa radiográfica”. Isto é, se um índio ou uma comunidade indígena reclama que determinadas terras lhes pertence, por terem sido ocupadas tradicionalmente por antepassados, em anos passados, isto só é válido se a presença dele, da comunidade indígena ou do antepassado em questão na terra reivindicada tenha ocorrido durante ou na data estipulada.

A decisão jurídica, de lógica cartesiana, ao menos trouxe a inevitável ressalva que a data da promulgação da Constituição não pode ignorar o massacre, esbulho, expulsão e remoção dos índios de suas terras tradicionais, legalizadas com títulos de propriedade ou atos jurídicos posteriores declarados nulos e extintos desde sempre pelo $\S 6^{\circ}$ do art. 231.

O próprio STF já tinha se manifestado nesse sentido no Recurso Extraordinário n. 416.144-3, que reconhece a ocupação indígena anterior à Constituição se comprovado o afastamento ou expulsão dos índios das suas terras:

O SENHOR MINISTRO GILMAR MENDES - Sr. Presidente, trata-se de um caso interessante, que fala um pouco dessa nossa experiência neste tema, que já se arrasta, acredito, desde a Constituição de 1891 .

Creio ser pacífico, mesmo entre os estudiosos do tema, que o art. 64 da Constituição de 1891, ao deferir aos Estados as chamadas "terras devolutas", pelo menos isso resulta dos estudos do célebre João Mendes, não teria repassado aquelas terras destinadas ao indigenato. Depois o texto de 1934, mais especificamente o texto de 1946, depois 1967, 1969, e, finalnente, o texto de 1988, todos eles enfatizaram o valor da posse indígena, inclusive os últimos enfatizando a propriedade da União e o usufruto em favor dos indígenas.

É certo, também, isto é algo pacífico, que eventual afastamento ou expulsão dos índios das terras a eles destinadas, ou por eles ocupadas, não constituía modus operandi ou faciendi para a eliminação da propriedade isso, parece-me, implícito, inclusive, na discussão. De modo que a União 
continuava a ser proprietária dessas terras. Também não me parece suficiente, para afastar a discussão que aqui se enceta e se coloca, a invocação daquelas famosas certidões da Funai sobre a não ocupação dessas terras pelos índios. [...]

No caso, como bem demonstrado pela eminente Relatora, não é disso que se cuida. Em 1998, houve a definição quanto à demarcação dessas terras e, desde então, arrastam-se as discussões com sucessivas medidas de efeito suspensivo. Isso trata um pouco, também, da nossa história e, inclusive, sobre o Judiciário e a própria Administração, que parecem trabalhar um pouco com o paradigma da eternidade. Tema como este acaba por ficar indefinido. ${ }^{12}$

Maior temor era que o voto sobre a Terra Indígena Raposa Serra do Sol, ao fixar a data da Constituição como marco fundamental, ignorasse a ressalva supramencionada, regredindo o direito indígena ao reconhecimento de seus territórios. Mas a redação do acórdão reafirmou expressamente o entendimento:

Retração que deve ser contemporaneamente espontânea, pois ali onde a reocupação das terras indígenas, ao tempo da promulgação da Lei Maior de 1988, somente não ocorreu por efeito do renitente esbulho por parte dos não índios, é claro que o caso já não será de perda da tradicionalidade da posse nativa. Será de violação dos direitos originários que assistem aos índios, reparável tanto pela via administrativa quanto judicial. Por isso é que servem as regras constitucionais de inalienabilidade e da indisponibilidade das terras indígenas, bem assim, a imprescritibilidade dos direitos sobre elas. ${ }^{13}$

Ainda assim, essa marca temporal é bastante criticada por ser portadora do vício intrínseco da anti-historicidade das relações humanas. Ao se fixar a data da promulgação da Constituição de 1988 de forma arbitrária, embora com certo simbolismo, concede-se um caráter quase divino à Constituição. Desconsidera-se o valor do Estatuto do Índio, sua historicidade e sua carga de tradicionalidade positiva, e soberbamente diminui-se o valor do passado indigenista brasileiro. Se interpretada de modo cabal a Constituição vira a algoz dos direitos dos povos indígenas, pois, impermeável a qualquer possibilidade de remissão das falhas históricas do indigenismo brasileiro e das injustiças perpetradas contra os índios. Deixa de ser possível analisar situações como aquelas em que comunidades indígenas foram removidas por convencimento das autoridades governamentais ou que fugiram da simples aproximação do homem branco ou de outros grupos indígenas, como acontece ainda hoje com muitos grupos autônomos. A própria Constituição democrática trouxe a muitos povos a 
consciência de seus direitos e a possibilidade da reivindicação de terras consideradas tradicionais, inclusive em razão do surgimento de organizações indígenas aptas e livres que puderam contestar os muitos casos de espoliação de terras indígenas ao longo do século 20 (MARÉS, 2003, p. 96).

$\mathrm{Na}$ prática, as tentativas de demarcação de terras Guarani, Kaingangue e tantas outras no sul e sudeste do País sofrerão com esse entendimento jurídico, aliado da antiga pressão política dos fazendeiros e políticos locais pelo não reconhecimento.

A mesma decisão que reafirma direitos territoriais dos povos indígenas exclui a ampliação de terras indígenas já demarcadas na condicionante n. $17 .{ }^{14}$ Novamente uma sentença peremptória como essa recai no mesmo erro de não recepcionar um sem número de situações peculiares. Falar em ampliação é uma impropriedade jurídica, tendo em vista que a terra indígena é aquela definida como tal sob os parâmetros dados pelo $\S 1^{\circ}$ do art. 231 da Constituição de 1988. Muitas terras indígenas foram reconhecidas pelo Estado brasileiro do Império ao governo militar. No entanto, a Constituição atual adotou um novo paradigma para o reconhecimento de terras indígenas, o que se faz exigir que todas as demarcações realizadas devam ser revistas e readequadas aos novos parâmetros, mesmo que sejam confirmadas em seus limites (VILLARES, 2009, p. 126). Não se pode falar então de ampliação, de diminuição ou de retificação em seus limites, mas de demarcação de acordo com o estabelecido constitucionalmente.

Mas o garrote com o qual se decidiu dar cabo do processo de demarcação de terras indígenas e, ao mesmo tempo, fazer regredir a política indigenista ao século 19 está nas condicionantes n. 5, 6, 7 e 11, ${ }^{15}$ que tratam da (não) participação e consulta das comunidades indígenas nos assuntos de uso e gestão de suas terras tradicionais. A explicação mais evidente para o retrocesso é o uso de artifícios cênicos de conceder o principal, a demarcação de uma terra indígena específica, enquanto se acolhem interesses divergentes, ainda que inconstitucionais, que procuram liberar o Estado para o aproveitamento autoritário dos recursos presentes nelas.

Não se pode falar em democracia sem o profundo respeito pelo direito à informação e participação dos cidadãos nas decisões políticas, principalmente aquelas que os afetem. Os índios merecem, por sua cultura e diferenciado entendimento do mundo, ser informados e participar das decisões e ações do Estado que atingem sua vida. Esse direito lhes é conferido pela Constituição, no $\S 3^{\circ}$ do art. 231 , no art. $6^{\circ}$ da Convenção 169 da OIT, e no art. $2^{\circ}$ da Lei n. 6.001/1973. São normas voltadas aos povos indígenas que garantem procedimentos apropriados de consulta através de suas instituições representativas sobre políticas e ações governamentais. A participação e o consentimento dos povos indígenas implicam decisões com maior consenso e, portanto, com mais legitimidade.

A decisão do STF, sob pressão das Forças Armadas e dos Estados, permitiu a intervenção irrestrita do Estado em terras indígenas. De pouco resultado prático, 
pois legalmente era pacífico o entendimento jurídico que possível a ampla ação do Estado nesses territórios (o Exército tem, inclusive, bases em inúmeras terras indígenas localizadas na fronteira com outros países), isso ainda dá margem ao ranço do autoritarismo tão caro ao nosso País em geral e às Forças Armadas em particular, que repudia a necessidade de negociação para suas ações, típicas de um regime democrático. Da mesma forma, viola o direito e retrocede a política com a suposição de que as comunidades indígenas não poderiam manter a autonomia de suas organizações sociais - que sempre respeitaram a estrutura de Estado brasileiro -, e decidir sobre a entrada, o trânsito e a permanência de pessoas não indígenas em suas terras, em sua casa. Direito conferido a todos e agora negado aos povos indígenas.

Se não interpretada de maneira adequada, as condicionantes n. 7, 12 e $13^{16}$ estabelecem que as terras indígenas poderão ser cortadas por estradas, linhas de transmissão de energia, oleodutos e gasodutos, sem qualquer compensação financeira ou territorial aos povos indígenas que nelas residam. O Supremo criou uma forma de transferência de território indígena (e quis impossibilitar seu aumento) de forma gratuita aos Estados e ao governo federal. Tenta eximir o Estado e empresas concessionárias de indenizações e pagamentos pelo passivo de inúmeras obras de infraestrutura colocadas goela abaixo dos povos indígenas, quando territórios destes não estavam reconhecidos ou reconhecidos por pura arbitrariedade do Estado.

Por fim, as condicionantes n. 8, 9, $10^{17}$ trazem a previsão de coexistência entre a demarcação de terras indígenas e as unidades de conservação da natureza. Por uma decisão do Supremo, sem nenhuma base legal e de forma arbitrária, definiu-se a competência do Instituto Chico Mendes, órgão vinculado ao Ministério do Meio Ambiente, para administrar a área de sobreposição. A decisão trouxe um retrocesso ao modelo que estava sendo negociado a duras penas ao longo dos últimos anos de administração conjunta entre os povos indígenas, a Funai e o Instituto Chico Mendes. $\mathrm{O}$ arranjo procurava a negociação e a compatibilidade entre os diversos regimes e usos como forma de resolver os inúmeros casos de sobreposição e da difícil relação entre povos indígenas e órgãos governamentais. O STF impôs uma vontade, a do Estado, numa alternativa teórica que esquece a história e a realidade local - ignora a comprovada e eficiente preservação ambiental em terras indígenas, independentemente de ações do órgão de defesa ambiental (BENSUSAN, 2004). Um exemplo concreto é a disputa em torno do Parque Nacional do Monte Pascoal, criado na década de 1930 tendo, dentre as justificativas, a presença do povo indígena Pataxó, hoje em permanente conflito com a administração do Parque.

Toda essa esquizofrenia se traduz no reconhecimento de um direito ainda cheio de incertezas, com incongruências e retrocessos que poderiam ser superados a partir da aplicação da Constituição e da legislação brasileiras, não fosse essa uma decisão da corte maior do país. Não se tratou no presente caso de negar validade a um enunciado normativo declarado inconstitucional. As 19 condicionantes foram criadas como 
enunciados de caráter geral, sendo a maioria sobre o relacionamento futuro do Estado com os povos indígenas, inclusive em relação à questão territorial. A demarcação da Terra Indígena Raposa Serra do Sol foi utilizada apenas como pano de fundo, pois declarada plenamente válida mesmo que não tenha obedecido as 19 condicionantes (não obedeceu ao menos a de número 19), ${ }^{18}$ além de terem como objeto problemas que não estavam presentes no caso concreto. Ainda assim, permanece a insegurança jurídica, já que a decisão deixa muitos pontos em aberto, o que força o STF a se manifestar novamente sobre o assunto.

O Supremo quis, na verdade, limitar a ação do Poder Executivo em sua responsabilidade constitucional de demarcar as terras indígenas e suplantar a inação do Poder Legislativo, que sequer aprovou em primeira votação um projeto, que tramita há mais de 15 anos na Câmara Federal, que pretende substituir o Estatuto dos Povos Indígenas, ou Lei n. 6.001, de 19.12.1973. Para tanto, talvez tenha passado a uma nova fase do controle de constitucionalidade, superando o papel da corte constitucional como legisladora negativa, a indicar a construção de soluções não expressas, ${ }^{19}$ criando o direito e a norma abstrata, com seus artigos, alíneas e parágrafos.

Essa nova postura ultrapassa o interesse voltado às questões indígenas. Ela interessa ao funcionamento do Poder Judiciário, principalmente ao papel de seu órgão máximo, o Supremo Tribunal Federal. Fica a eterna pergunta da legitimidade dos juízes de criar o direito, agora colocada sob a óptica da limitação dos direitos sociais.

As comunidades indígenas que habitam a Terra Indígena Raposa Serra do Sol aguardaram pacientemente os mais de 25 anos do procedimento de demarcação, com inúmeras interrupções judiciais, sendo um dos mais longos julgamentos do Supremo. Enquanto isso, suas terras foram invadidas; suas casas e escolas, queimadas; lideranças indígenas, mortas. Mereciam mais julgamento e menos demonstração de poder. A demora, o suspense e os finais imprevisíveis só combinam com espetáculos, não com os julgamentos do Supremo Tribunal do Poder Judiciário.

Mas, por ora, o STF sai de cena.

: ARTIGO APROVADO (28/08/2009) : RECEBIDO EM 31/07/2009

1 Nascido em Belo Horizonte, MG, Alfredo Ceschiatti (1918-1989) foi escultor, desenhista e professor na Universidade de Brasília. Tornou-se conhecido por criar obras para decoração de prédios projetados por Oscar Niemeyer, 
sendo as mais conhecidas A Justiça instalada no STF; Os anjos e Os evangelistas, na Catedral de Brasília; e As banhistas, no Palácio da Alvorada.

2 É necessária uma resumida exposição para entender a complexidade do caso. O procedimento administrativo demarcatório da Terra Indígena Raposa Serra do Sol teve início em 1977 e passou por uma longa batalha política e judicial. Foi somente em 1993 que um grupo de técnicos da Funai apresentou uma proposta de limite territorial, um laudo antropológico e um levantamento fundiário que atestavam ter 1.678.800 hectares as terras dos povos indígenas Macuxi, Patamona, Tauperang e Uapixana da Raposa Serra do Sol. Ainda em 1993, após a aprovação e publicação do estudo de demarcação da terra indígena, a Funai encaminhou seu relatório ao Ministério de Justiça para aprovação.

Após anos sem seguimento, sobreveio o Decreto n. 1.775/96, que passou a regular os procedimentos de demarcação. Por sua força, foram apresentadas contestações por particulares e também pelo Estado de Roraima à identificação da Terra Indígena Raposa Serra do Sol. Em dezembro de 1996 o então ministro da Justiça, Nelson Jobim - e futuro ministro do STF -, julgou improcedentes as contestações administrativas apresentadas, mas, ao mesmo tempo, excluiu a sede do município de Uiramutã e outras vilas, além de algumas propriedades de particulares da área reconhecida, determinando que os autos do procedimento demarcatório voltassem à Funai para que os limites da terra indígena fossem refeitos. Decisão essa sem qualquer fundamentação jurídica ou técnica. Após protestos das organizações e povos indígenas e dois anos de impasse o procedimento foi reenviado pela Funai ao Ministério da Justiça para reconsideração. Organizações indígenas e de direitos humanos nacionais e internacionais passaram a denunciar as graves violações e violências a que se submetiam os povos indígenas da região enquanto sua situação permanecia indefinida e aumentaram a pressão sobre os órgãos da administração para que os povos indígenas da Raposa Serra do Sol tivessem seus direitos garantidos em conformidade com o artigo 231 da Constituição Federal.

Em 11.12.1998 o Ministro da Justiça, Renan Calheiros, declarou pela Portaria MJ n. 820 ser de posse permanente dos povos indígenas a totalidade da Terra Indígena Raposa Serra do Sol; em 1999, a demarcação física foi efetuada, restando apenas o ato administrativo presidencial de homologação.

Porém, ocupantes ilegais, fazendeiros invasores e o próprio governo do Estado de Roraima insurgiram-se contra essa portaria ministerial. Ingressaram com ações judiciais na Justiça Estadual (ações possessórias), Federal (ações possessórias) e no STF (ação cautelar; ação popular; ação civil originária; ação direta de inconstitucionalidade; mandado de segurança) contra a demarcação da terra indígena. Instaurou-se, também, a usurpação deliberada da terra indígena, além da violência moral e física contra as comunidades indígenas. O clima de instabilidade se agravou quando o ato administrativo de demarcação da terra indígena foi impedido com a concessão de liminares judiciais.

As inúmeras ações possessórias, a ação popular, os mandados de segurança e os pedidos de liminares contra a demarcação da área contínua da Raposa-Serra do Sol, na primeira ou segunda instâncias da Justiça, impediram por diversas vezes o Estado brasileiro de finalizar o processo de demarcação da terra indígena.

Com a posse, em 2003, do presidente Luís Inácio Lula da Silva, cuja promessa de campanha aos povos indígenas foi finalizar a demarcação da terra Raposa Serra do Sol, aumentaram as esperanças de uma solução. Esse anúncio em favor da proteção dos índios e suas terras, por outro lado, acentuou o clima de tensão e os ataques violentos contra os índios na região.

O juiz da $1^{\mathrm{a}}$ Vara Federal da Seção Judiciária de Roraima, notório opositor da demarcação, deferiu nova liminar na ação popular ajuizada em 1999 por advogados roraimenses e litisconsortes os deputados Luciano Castro (PL-RR) e Suely Campos (PP-RR), o Senador Mozarildo Cavalcanti (PPS-RR), e o índio Caetano Raposo que suspendeu novamente, ainda que de forma parcial, os efeitos da Portaria n. 820. As ações judiciais tinham como objetivo ganhar tempo para acelerar as ocupações por não índios, o que responderia aos interesses dos colonizadores da área e do Estado de Roraima. Em julho de 2004, o mesmo juiz ordenou a saída dos índios da TI Raposa Serra do Sol, reintegrando os fazendeiros na posse da terra demarcada.

A Funai, então, peticionou ao Supremo Tribunal Federal no âmbito da Reclamação n. 2388 apresentada pelo Ministério Público Federal, pedindo o sobrestamento das ações possessórias e a suspensão das medidas cautelares proferidas na ação popular. Nessa altura, ficara evidente o conflito federativo entre o Estado de Roraima e União, o que levou o STF, em outubro de 2004, a se decidir competente pelo julgamento de todas as ações que dizem respeito à demarcação da TI Raposa Serra do Sol, afastando as liminares e suspendendo as ações possessórias. A substituição administrativa da Portaria n. 820/1998 pela edição de uma nova Portaria do Ministro da Justiça Márcio Thomaz Bastos, Portaria n. 534/2005, que procurava conciliar os diversos interesses envolvidos sem deixar de reconhecer por inteiro o território indígena, possibilitou a homologação da demarcação da Terra Indígena Raposa Serra do Sol através do Decreto de 15.04.2005.

Em trabalho coordenado entre os Poderes Executivo e Judiciário, a nova Portaria e a homologação possibilitaram que o STF apreciasse todos os processos judiciais sobre o caso, decidindo pela sua extinção dada a perda do objeto, ou seja, porque a Portaria n. 820 - fundamento da ação popular, das liminares e das ações possessórias - deixava de existir. Decisão depois confirmada definitivamente no julgamento das Reclamações n. 2833, 3331 e 3813 em junho de 2006. Finalmente em 2009, o STF apreciou o mérito da questão no julgamento de uma medida cautelar ajuizada pelos ocupantes quando o Poder Executivo iniciou os trabalhos de desocupação da terra indígena, colocando um ponto definitivo no caso. 
3 Memoriais são esclarecimentos ofertados pelas partes antes do julgamento de uma ação por um tribunal. Não há disciplina processual a regular a sua apresentação, sendo uma simples faculdade dos litigantes, ainda que a impossibilidade de sua apresentação possa causar anulação de julgamentos (HC 85.512 do STF).

4 As questões de ordem devem ser decididas antes do pronunciamento do mérito da demanda. Independentemente da manifestação das partes, cabe ao magistrado emitir seu juízo sobre as questões de ordem, que no processo são geralmente ligadas aos pressupostos processuais e condições da ação, listados nas disposições do art. 267 , $\S 3^{\circ}$, com reforço das determinações do art. 301, $4^{\circ}$, ambos do Código de Processo Civil. Podendo ser listadas, entre outras, as questões sobre inexistência ou nulidade de citação; incompetência absoluta; inépcia da petição inicial; perempção; litispendência; coisa julgada; conexão; incapacidade da parte, defeito de representação ou falta de autorização; carência da ação; falta de caução ou de outra prestação, que a lei exige como preliminar.

5 Impossível não transcrever uma parte de sua defesa oral: “A terra indígena não é só casa para morar, mas o local onde se caça, onde pesca, onde se caminha e onde os povos indígenas vivem e preservam sua cultura. A terra não é um espaço de agora, mas um espaço para sempre. Queremos viver conforme nossos usos e costumes. Conforme nossas tradições, num ambiente de harmonia e respeito com todos".

6 O Ministro Menezes Direito pediu vista no último caso polêmico em julgamento no STF, sobre a constitucionalidade da Lei de Biossegurança no que se refere à utilização de células-tronco em pesquisas científicas.

7 Verificar o julgamento do MS 21.896/PB sobre a demarcação da Terra Indígena Jacaré de São Domingos, o MS 25.463/DF sobre a demarcação da Terra Indígena Nanderu Marangatu, a ACO 312/BA sobre a Terra Indígena Caramuru Paraguassu, e os MS 21.649 e MS 24.045.

8 O Brasil ratificou a Convenção 169 da Organização Internacional do Trabalho, por meio do Decreto Legislativo n. 143 de 20.06.2002, entrando em vigor em 2003, com força de lei ordinária, segundo jurisprudência do STF e posterior Emenda Constitucional n. 45 (2004), que acrescentou um parágrafo terceiro ao art. $5^{\circ}$.

9 Yamada, Erika Magami. International Human Rights Law in the context of Indigenous Peoples: Moving From Legislation To Implementation: Lands rights' cases at the Brazilian Federal Supreme Court. Dissertação SJD apresentada na University of Arizona, Rogers E. College of Law, 2009, p.14.

10 Pendentes de decisão judicial são muitas as terras indígenas, com especial atenção para os casos da Terra Indígena Pataxó-Hã-Hã-Hãe que espera 27 anos por uma definição do próprio STF, Ñanderu Marangatu do povo Guarani Caiová, também pendente de julgamento no STF e, Marawãtsede do povo Xavante etc.

11 Pinheiro, 2009, p. 20.

12 STF - RE n. 416.144-3/MT, voto min. Gilmar Mendes, rel. Min. Ellen Gracie, DJ. 01.10.2004.

13 STF - PET n. 3.388, voto min. rel. Carlos Britto, DJ. 25.09.2009.

14 “17 - É vedada a ampliação da terra indígena já demarcada. 1 - O usufruto das riquezas do solo, dos rios e dos lagos existentes nas terras indígenas pode ser relativizado sempre que houver como dispõe o artigo $123\left(\S 6^{\circ} \mathrm{da}\right.$ Constituição Federal) o relevante interesse público da União na forma de Lei Complementar.”

15 “5 - O usufruto dos índios não se sobrepõe ao interesse da Política de Defesa Nacional. A instalação de bases, unidades e postos militares e demais intervenções militares, a expansão estratégica da malha viária, a exploração de alternativas energéticas de cunho estratégico e o resguardo das riquezas de cunho estratégico a critério dos órgãos competentes (o Ministério da Defesa, o Conselho de Defesa Nacional) serão implementados independentemente de consulta a comunidades indígenas envolvidas e à Funai; 6 - A atuação das Forças Armadas da Polícia Federal na área indígena, no âmbito de suas atribuições, fica garantida e se dará independentemente de consulta a comunidades indígenas envolvidas e à Funai; 7 - O usufruto dos índios não impede a instalação pela União Federal de equipamentos públicos, redes de comunicação, estradas e vias de transporte, além de construções necessárias à prestação de serviços públicos pela União, especialmente os de saúde e de educação. [...] 11 - Deve ser admitido o ingresso, o trânsito, a permanência de não índios no restante da área da terra indígena, observadas as condições estabelecidas pela Funai.” 
16 “12 - O ingresso e permanência de não índios não pode ser objeto de cobrança de quaisquer tarifas ou quantias de qualquer natureza por parte das comunidades indígenas; 13 - A cobrança de tarifas ou quantias de qualquer natureza também não poderá incidir ou ser exigida em troca da utilização das estradas ou equipamentos públicos, linhas de transmissão de energia ou de quaisquer outros equipamentos e instalações colocadas a serviço do público tenham sido excluídos expressamente da homologação ou não.”

17 "8 - O usufruto dos índios na área afetada por unidades de conservação fica sob a responsabilidade imediata do Instituto Chico Mendes de Conservação da Biodiversidade; 9 - O Instituto Chico Mendes de Conservação da Biodiversidade responderá pela administração da área de unidade de conservação, também afetada pela terra indígena, com a participação das comunidades indígenas da área, que deverão ser ouvidas, levando em conta os usos, as tradições e costumes dos indígenas, podendo, para tanto, contar com a consultoria da Funai; 10 - O trânsito de visitantes e pesquisadores não índios deve ser admitido na área afetada à unidade de conservação nos horários e condições estipulados pelo Instituto Chico Mendes.”

18 A condicionante n. 19 é uma ressalva acrescida pelo Presidente do Supremo Tribunal Federal, min. Gilmar Mendes, que exige a participação dos Estados e Municípios no processo de demarcação de cada terra indígena.

19 ADI/MC 1.949, ministro Sepúlveda Pertence, p. 193.

\section{REFERÊNCIAS BIBLIOGRÁFICAS}

GOMES, Mércio Pereira. Porque sou rondoniano. Revista de Estudos Avançados, v. 23, n. 65, pp. 173-191, 2009. MARÉS DE SOUZA FILHO, Carlos Frederico. Multiculturalismo e direitos coletivos. In: SOUSA SANTOS, Boaventura de (org). Reconhecer para libertar: os caminhos do cosmopolitismo multicultural. Rio de Janeiro: Civilização Brasileira, 2003.

PINHEIRO, Victor Marcel. O STF e o mito do legislador negativo. In: COUTINHO, Diogo R.; VOJVODIC, Adriana M. Jurisprudência constitucional: como decide o STF? São Paulo: Malheiros Editores, 2009.

VILLARES, Luiz Fernando. Direito e povos indígenas. Curitiba: Juruá Editora, 2009.

YAMADA, Erika Magami. International Human Rights Law in the context of Indigenous Peoples: Moving From Legislation To Implementation: Lands rights' cases at the Brazilian Federal Supreme Court. Dissertação SJD apresentada na University of Arizona, Rogers E. College of Law, 2009.

\author{
SCLN, 210, Bloco C sala 112, \\ $70862-530$ \\ Brasília - DF - Brasil \\ erimagamiyamadadgmail.com
}

Erica Magami Yamada

Advogada do Instituto Socioambiental

Doutora em Direito e Política Indígena PELA UnIVERSIDADE do ARIZONA

\section{Luiz Fernando Villares}

